\title{
Regional agreements, higher education and representations of Indigenous Australian reality
}

\section{(Why wasn't I taught that in school?)}

\author{
Greg McConville
}

\begin{abstract}
The educational struggles of Indigenous peoples are fundamentally and unequivocally concerned with the right of Indigenous peoples to be indigenous. ${ }^{1}$
\end{abstract}

\section{Introduction}

The rights of Indigenous peoples to self-identify, self-determine and self-represent have been asserted both locally and internationally. The Coolangatta statement, the Kari-Oca declaration entitled 'Indigenous Peoples' Earth Charter'2 and declarations of the World Indigenous Youth Conference held in Darwin 1993, are recent examples of how Indigenous peoples have stated what to many should be obvious: Indigenous peoples know themselves, their experiences, their land and knowledge systems better than anyone else, and that Indigenous peoples have the right to shape the representation of these realities not only among themselves, but also within colonised nations.

United Nations covenants and declarations have appeared to accept these assertions of the rights of Indigenous peoples to engage with, to shape and to benefit from all levels of education. The record of individual governments, including Australian governments at Commonwealth, state and territory levels, is another matter entirely. Since colonisation, Indigenous Australians have at various times been denied the right to maintain their own knowledge systems, have been re-defined within western scientific and anthropological constructs, and prevented by racism, marginalisation and disadvantage from gaining the economic and social mobility available to non-Indigenous Australians through the education system. While much government policy is based on the assumption that poor educational participation and outcomes stem from a 'deficit' within Indigenous Australians, there is compelling evidence that it is the nature of the education system and the policies surrounding it that entrench Indigenous educational disadvantage.

This paper addresses the rights asserted by Indigenous peoples and recognised by the United Nations to self-identify, self-determine and self-represent. It then examines Australian performance in the area of higher education relating to those asserted rights, and presents some options aimed at enshrining Indigenous education as an enforceable right rather than a matter of administrative and political goodwill.

\footnotetext{
${ }^{1}$ Coolangatta Statement 1999. $\quad{ }^{2}$ Kari Oca Statement 1993.
} 


\section{Indigenous education as a right}

In his welcome to country at the start of the Treaty Conference, Mr Mort Hansen, of the Metropolitan Council of Noongar Elders, spoke of his school experiences. Learning the English alphabet, while being told that learning about Aboriginality was bad, were characteristics of Mort's experience shared by many Aboriginal and Torres Strait Islander peoples.

During the years 1971 to 1982, I attended primary school in East Keilor, and attended secondary school in Moonee Ponds and West Essendon. Repeatedly, the matter of the presence of Aboriginal people prior to European contact was discussed among students, but was rarely the subject of any formal teaching. In response to questions about where Aboriginal people went, teachers would sometimes reply that Aboriginals had gone to the desert, because they liked it there.

In about 1974, my parents by chance took me to the office of the Keilor Historical Society, where I learned of the discovery of the Keilor Cranium in 1940. Keilor, as the cranium was known, had been found in a sand bank by the Maribyrnong River, and had been carbon-dated as over 12,000 years old. That Aboriginal people had roamed the plains for at least 40,000 years, along with massive creatures such as Diprotodons, ${ }^{3}$ was a revelation to me at that time. I asked myself: 'Why wasn't I taught that at school?'

In fact, in all of my years of schooling in that region, the Keilor Cranium was never mentioned in the classroom.

Mort Hansen's experiences, and my experiences, are to some extent the flip side of the same coin. While the education system denied Mort the right to learn his culture and his peoples' history, the truth of Aboriginal sovereignty was held back from me.

Surely, just as Mort Hansen had a right to learn his own culture and traditions, I had a right to know the truth about sovereignty, colonisation and dispossession. The location of the educational system as an instrument of colonisation, denied us both this right. Both Indigenous and non-Indigenous Australians should have this right today.

Prominent Indigenous Australian educators have, through their experiences as Indigenous Australians and as educators, contributed to the development of a wealth of material which addresses how the educational experience should be informed from Indigenous perspectives, and how in turn the education system must engage with the reality and experiences of Indigenous Australians.

In this paper, I have focused principally on the Coolangatta Statement on Indigenous Peoples Rights in Education, ${ }^{4}$ recognised by the United Nations. The work of four Indigenous Australians in contributing to the Statement should be acknowledged: Dr Bob Morgan, Japanangka West, Martin Nakata and Dr Paul Hughes were members of the 1993 task force (drawn from the United States, Canada, Aotearoa and Australia), which was charged with the responsibility of drafting the Statement.

Intended as a dynamic document which can evolve and change, the Statement contains a concise description of how education systems should be transformed to give effect to

\footnotetext{
3 Keilor Historical Society, 1992, refers to Diprotodon as 'measuring two metres high $\quad{ }^{4}$ Coolangatta Statement 1999. and three metres in length ... believed to be the largest marsupial ever to have lived'.
} 
fundamental human rights as asserted by Indigenous Peoples. Following is an extract from the Preamble to the Coolangatta Statement:

This Statement speaks to the inherent rights of Indigenous peoples as declared in Article 27 of the International Covenant on Civil and Political Rights:

In those States in which ethnic, religious or linguistic minorities exist, persons belonging to such minorities shall not be denied the right, in community with the other members of their group, to enjoy their own culture, and to profess and practice their own religion, and to use their own language. ${ }^{5}$

The Coolangatta Statement ${ }^{6}$ also refers to Article 26 of the United Nations Declaration of Human Rights, which addresses the right of all peoples to participate in all levels of education to assist their full development as humans, and to strengthen respect for human rights and fundamental freedoms.

While recognising these instruments are important, the Coolangatta Statement identifies a number of limitations in the extent to which they protect equal access, ensure that Indigenous parents can choose the kind of education available to their children, enable Indigenous peoples to enjoy their own cultures and communities, and facilitate language use and reclamation. In light of these inadequacies, the Statement describes self-determination in Indigenous Education as embodying rights to:

- control/govern Indigenous education systems;

- have learning facilities recognise, respect and promote Indigenous values, philosophies, and ideologies;

- develop and implement culturally inclusive curricula;

- import the wisdom of Indigenous elders to the educational process;

- determine criteria for evaluation and assessment;

- develop standards for the gifted and talented;

- promote use of Indigenous languages;

- establish parameters and ethics for Indigenous education research;

- apply culturally appropriate teacher training;

- participate in teacher accreditation and selection;

- determine criteria for the registration and operation of learning facilities; and

- choose the nature and scope of education without prejudice. ${ }^{7}$

In addition to the articulation of these rights, a number of important observations are made. The importance of land to language and culture, the legitimacy of Indigenous languages and knowledge systems, and the diversity which exists within and between Indigenous peoples are all identified by the Coolangatta Statement as matters to be recognised in the transformation of educational systems based on Indigenous pedagogy. That is not to say that the Indigenous educational experience should occur away from and separate to mainstream or westernised education. Rather, it is about ensuring that mainstream institutions, whether schools, TAFE

${ }^{5}$ Coolangatta Statement 1999: 1. $\quad{ }^{6}$ Coolangatta Statement 1999: $2 . \quad{ }^{7}$ Coolangatta Statement 1999: 6. 
colleges or universities, incorporate in all areas of their activity Indigenous terms of reference and values as articulated by Indigenous peoples. The role of non-Indigenous people therefore is to respect and adhere to Indigenous community values and aspirations, while the role of institutions is to accept and uphold the rights of Indigenous peoples as non-negotiable. ${ }^{8}$

For the purposes of this paper, the philosophies embodied in the Coolangatta Statement represent a useful basis on which to assess the nature and performance of the Australian higher education system relating to Indigenous Education. The very term Indigenous Education should therefore be taken as representing the rights, responsibilities and aspirations discussed above.

\section{The performance of higher education in Australia}

The role of education for Indigenous Australians, as distinct from Indigenous Education, in colonised Australia has historically been aligned to government priorities and policies. The establishment of institutions of learning at all levels has reflected the various stages of the relationships between Indigenous and non-Indigenous Australians. The inherent privileging of westernised knowledge systems in establishing those institutions, without reference to Indigenous peoples, in the first instance relegated Indigenous Australians to being subjects of the dominant education system, rather than active participants in it. For higher education institutions in particular, serious 'business' exists arising from the nature of their foundation. Universities researched and taught the philosophies which were used to justify policies of separation and assimilation, acquired (stole) many objects of cultural significance thus assisting the cultural dispossession of many Indigenous Australian peoples, while disciplines associated with the pastoral and mining industries contributed to material dispossession. The land on which universities are situated was never ceded, and teaching and research about Indigenous Australian peoples was established from entirely non-Indigenous frameworks.

I will examine four important areas in which our performance can be assessed against the principles enshrined in the Coolangatta Statement. These are governance, Indigenous Education programs, Aboriginal and Torres Strait Islander employment within universities, and research.

\section{Governance}

Indigenous involvement in university governance structures as a right should enable the pursuit of many of the principles embodied in the Coolangatta Statement. Controlling and governing Indigenous Education within universities, developing culturally inclusive curricula, and the development of appropriate research ethics and teacher training among other matters cannot occur without direct involvement of Indigenous Australians in the governance structures themselves.

Indigenous Education does not exist as a right; rather universities exist as products of colonial parliamentary and legal systems. The various acts which establish universities create obligations, among other things, to provide for the educational and research needs of the communities and regions in which they are situated, and prescribe categories of membership on governing bodies aimed at ensuring that those needs are articulated and met. ${ }^{9}$ That legislators defined those communities within entirely western constructs is evidenced by the fact that of all legislation establishing higher education institutions, the only Act requiring

${ }^{8}$ Coolangatta Statement 1999: 7. $\quad{ }^{9}$ See e.g. Charles Sturt University Act 1989 (New South Wales). 
Aboriginal or Torres Strait Islander representation on a governing body is that establishing the Bachelor Institute of Indigenous Tertiary Education (BIITE).$^{10}$ While it is positive that the need for this representation has been recognised in establishing BIITE as an institution for educating Indigenous Australians, Indigenous Australians do not have a legislated right to participate in the management and oversight of any Australian university. This is symptomatic of what Dr Bob Morgan describes as the 'guest paradigm' whereby the presence of Indigenous Australians within universities as students, teachers, researchers, and advisors is dependent on the goodwill of those institutions, and of the governments which fund them.

Despite this reliance, there have been some significant advances made in making universities more responsive to Indigenous Australian community needs and aspirations. To many, the importance of education to Aboriginal and Torres Strait Islander peoples was emphasised by Recommendation 202 of the Royal Commission into Aboriginal Deaths in Custody:

That where such courses are not already available, suitable training courses to provide necessary administrative, political and management skills should be available for persons elected to regional councils of ATSIC, elected to, appointed to, or engaged in Aboriginal organisations involved in the delivery of services to Aboriginal people and other community organisations. The content of such training courses should be negotiated between appropriate education providers (including Aboriginal education providers) other appropriate Aboriginal organisations and government. Such courses should be funded by government and persons undertaking such course should be eligible for such financial assistance in the course of studies as would be available under ABSTUDY guidelines. ${ }^{11}$

As more and more Aboriginal and Torres Strait Islander students and staff moved into universities, issues of appropriate course content, adequate funding and the accommodation of community and cultural responsibilities have been identified as matters for action. With the advent of the modern reconciliation movement, the role of education as one of the most important areas in which reconciliation can be given some substance is becoming more apparent. Universities are now considering it appropriate to adopt 'Reconciliation Statements', create advisory bodies to advise on 'Indigenous Content', and in some cases make arrangements for the return of objects of cultural significance. At no point, however, have any of these advances been enshrined as non-negotiable rights in the terms of the Coolangatta Statement, which states:

\section{Indigenous Education Programs}

2.5 Non-Indigenous peoples through the various levels of government and bureaucracy have an over-riding responsibility to accept and uphold the educational rights of Indigenous peoples and to know that these rights and freedoms are non-negotiable. ${ }^{12}$

The events surrounding the Commonwealth Government cuts to the ABSTUDY scheme provide a strong indicator of how politically vulnerable Indigenous Education programs are. The ABSTUDY scheme, an income support scheme for Indigenous Australian students, was

\footnotetext{
${ }^{10}$ Batchelor Institute of Indigenous Tertiary Education Act 1999 (Northern Territory). 
introduced in 1969. It aimed to improve the participation and success rates for Indigenous students, and was attributed as the cause of those improvements up to $1998 .{ }^{13}$ During the 1996 Federal Election, ABSTUDY was portrayed by extremist political forces as discriminating against non-Indigenous Australians because it provided benefits in excess of those available to non-Indigenous Australian students. Indigenous Australians, it was argued, were on a gravy train of government handouts devised by do-gooders in the 'Aboriginal Industry', and ordinary Australians were missing out.

No amount of research, lobbying or advocacy was enough to convince the Howard Government that criticism of ABSTUDY was unwarranted. Despite the findings of research undertaken by Deakin University that changes proposed to ABSTUDY would significantly disadvantage 94.3\% of Aboriginal and Torres Strait Islander students, ${ }^{14}$ the Howard Government proceeded to implement those changes on 1 January 2000, thus reducing the income support available to most Indigenous Australian students.

Department of Education, Employment, Training and Youth Affairs (DETYA) student statistics for the year 2000 show that between 1999 and 2000, the number of Indigenous students commencing higher education study had decreased by $15.2 \%$, while overall enrolments had fallen by $8.1 \%$. This was a matter of concern for many in the higher education sector, with the National Tertiary Education Union (NTEU), Australian Vice-Chancellors Committee (AVCC), National Union of Students (NUS) and Council of Australian Postgraduate Associations (CAPA) all pointing to the ABSTUDY changes as underlying the fall in participation.

In response to widespread criticism, DETYA (now the Department of Education, Science and Technology - DEST) Minister Kemp and later Minister Nelson argued that Indigenous Australian students were choosing to enrol in Vocational Education and Training (VET) programs instead of higher education. ${ }^{15}$

In reality, growth in Aboriginal and Torres Strait Islander enrolments and overall participation in higher education slowed to the same extent, around 12.5\%, between 1999 and 2000 . Against the background of strong growth in participation from the 1970s onwards, the decline in enrolments which corresponded with the timing of the ABSTUDY changes strongly demonstrated the relationship between ABSTUDY and participation in both higher education and VET. ${ }^{16}$ More importantly, the fact that a program developed in consultation with Indigenous Australian communities could be abolished in the face of widespread disagreement and criticism, demonstrated the extent to which such a scheme is not only dependant on political goodwill, but also vulnerable to political bad faith.

The net effect of the gutting of ABSTUDY as a scheme for student income support, together with the abolition of Higher Education Merit Equity Scholarships, real reductions in Indigenous Support Funding and other policy changes, is a reversal of sustained improvement:

Indigenous Australian students now comprise only $1.01 \%$ of the nonoverseas (university) student cohort: the lowest such figure since 1993 ... These figures are now at pre 1991 levels. Ten years of growth in participation of Indigenous Australians in higher education have been reversed in the space of two years. ${ }^{17}$

\footnotetext{
${ }^{13}$ Stanley and Hansen 1998. $\quad{ }^{15}$ DEST 2002: $21 . \quad{ }^{17}$ Bunda and McConville 2002: 13, 18.

${ }^{14}$ Deakin University $1999 . \quad{ }^{16}$ Bunda and McConville 2002: 13, 18.
} 


\section{Aboriginal and Torres Strait Islander employment within universities}

\subsubsection{The teacher is a facilitator of learning, one who promotes} achievement and success. In this context culturally appropriate environments are employed to reinforce knowledge being imparted to the learner, reaffirming the learner's significant place in the world. ${ }^{18}$

Mentoring and guidance by Indigenous Australian staff is essential to student progress. In the year 2000 Indigenous Australian staff comprised only $0.67 \%$ of university staff. ${ }^{19}$ To achieve proportionate employment the number of Indigenous Australian staff would need to almost triple. In 2000 there were no Commonwealth-funded schemes aimed at increasing Aboriginal and Torres Strait Islander employment in the public sector and universities, despite the Royal Commission into Aboriginal Deaths in Custody recommendations to implement such schemes. ${ }^{20}$

The status of Indigenous staff in universities is much less secure, on average, than their nonIndigenous counterparts. Limited term employment in Indigenous Units/Centres is much more prevalent than in universities generally. Within Indigenous Units, an estimated $45.4 \%$ of staff were in 2000 employed on a limited term basis, compared to $32.7 \%$ within the sector. Clearly, staff employed in Indigenous Units/Centres did not enjoy the same security of tenure as staff within the sector generally, and this affects Indigenous staff more than non-Indigenous. Within Indigenous Units/Centres, Indigenous staff were and are more likely to be employed on limited term than their non-Indigenous counterparts. ${ }^{21}$ Strong evidence exists of systemic discrimination against Indigenous staff in the area of tenured university employment.

The consequences of this tenuous position for Indigenous Australian university staff, and for the university and its students, are numerous. Contract employment places all staff in a position where they could be subjected to arbitrary action, but for Indigenous Australian staff it may limit their capacity to be free to disagree with senior colleagues, or to challenge university teaching and research from their own Indigenous perspective. The fact that nonIndigenous staff are more secure in positions within centres established for Indigenous Education questions whether opportunities are being created for genuine Indigenous control of Indigenous Education.

The employment status of Aboriginal and Torres Strait Islander people in universities limits involvement of their communities in pedagogical processes, while under-representation of Indigenous staff contributes to a less culturally responsive environment for students.

\section{Research}

The particular synergies between teaching and research across various fields of academic endeavour distinguish universities from other educational institutions, and present unique opportunities for Indigenous Australians to shape what is documented, taught and learned. In the processes of determining how Indigenous Australians are represented within academic endeavour, their involvement in managing the process of inquiry and debate about them is essential. This involvement takes place in the form of postgraduate research and research supervision, involving support from DEST, and the Australian Research Council (ARC).

\footnotetext{
${ }^{18}$ Coolangatta Statement 1999: clause 2.4.3. $\quad{ }^{20}$ Royal Commission into Aboriginal $\quad{ }^{21}$ NTEU 2000, and DETYA $2000 a$.

${ }^{19}$ DETYA 2000a. Deaths in Custody 1991.
} 
Aside from the valuable work undertaken with the assistance of the Australian Institute for Aboriginal and Torres Strait Islander Studies (AIATSIS), there is limited research activity about Indigenous Australians and very little of it is reserved as the specific domain of Indigenous Australian scholars. In all, the ARC funded 2 fellowships, 23 large grants and 11 SPIRT $^{22}$ grants of interest to Indigenous Australians in $2000 .{ }^{23}$ The total amount of funding allocated to these projects was $\$ 1,578,396 .{ }^{24}$ This limited funding, was spread across a range of projects which included:

- natural hazard vulnerability, awareness and mitigation strategies for remote and Indigenous communities in Northern Australia;

- GIS (Global Information System) for Natural and Cultural Resource Management by Indigenous People;

- a Research Training Project Examining Leadership in Indigenous Early Childhood Settings in Northern NSW;

- Accountability and Indigenous Service Delivery: Mechanisms, Policy and Process in Rethinking Indigenous Self-determination: Politics, Land and Law in Australia; A demographic and socio-medical history of the Aboriginal people of Victoria, 1800-2000: colonisation and epidemiological transitions;

- the impact of premature mortality on Aboriginal men's constructs of risk and health; and

- a study of Aboriginal children removed in Australia, mainly twentieth century.

Of all funding available for research of direct relevance to Indigenous Australians, in 2000 some 9\% was specifically allocated to Indigenous Australian scholars in the form of the Indigenous Researchers Development Scheme. ${ }^{25}$ The low percentage of Indigenous postgraduate researchers ( $0.6 \%$ of all postgraduate researchers in 1999) meant that the involvement of Indigenous Australian researchers in projects such as those outlined above is seriously limited.

This lack of participation in research by Indigenous Australians is consistent with the overall effects of the past purpose of education for Indigenous peoples, as the Coolangatta Statement succinctly describes:

1.3.1 Historically, Indigenous peoples have insisted upon the right of access to education. Invariably the nature, and consequently the outcome, of this education has been constructed through and measured by non-Indigenous standards, values and philosophies. Ultimately the purpose of this education has been to assimilate Indigenous peoples into non-Indigenous cultures and societies. ${ }^{26}$

Aside from direct involvement in the conduct of research, the problems confronting Indigenous Australian peoples in shaping research about them has been well documented. Hart and Whatman describe where Indigenous Australians are placed by western notions of

${ }^{22}$ Strategic Partnerships Industry-Research and Training Scheme, now known as Linkage grants.

${ }^{23}$ The definition of 'of Interest to Aboriginal and Torres Strait Islander peoples' is from AIATSIS 1999: 3.

\footnotetext{
${ }^{24}$ See www.ARC.edu/gov.au The funding includes projects relating to Indigenous peoples' languages, history, culture and art, also projects approved in 1998 and 1999 where funding continued to year 2000.

25 NTEU 2001: 16.

${ }^{26}$ Coolangatta Statement 1999: clause 3.1.1.
} 
inquiry and research. They argue that while Australia's Indigenous people are excluded from defining the research values of our education sytem through any direct input, non-Indigenous scholars tend to consider that Indigenous people are included (in the acceptance of research values) because research is perceived to benefit the whole community. ${ }^{27}$

Hart and Whatman articulate a number of assumptions identified by James Cook University, in 1995, as contributing to the disempowerment of Indigenous Australian communities in research endeavours. These include the following:

a) the assumed right of researchers to undertake research into the culture of Indigenous Australians;

b) the notion that cultural knowledge recorded in research reports is the only legitimate or lasting medium to protect knowledge and data exposed by such research;

c) that research needs to expose apparent dominant and latent primitivism of Indigenous societies;

d) the assumption that all knowledge, including Aboriginal and Torres Strait Islander knowledge, should be placed in the public domain;

e) that only non-Indigenous researchers do research well;

f) the belief that the privatisation of knowledge is not a social or cultural premise in Indigenous Australian cultures;

g) the assumption that the right of all people to access all knowledge is also an Indigenous cultural absolute;

h) the belief that the apparent absence of sophisticated Indigenous infrastructural mechanisms to maintain cultural continuity requires Western research and techniques to preserve culture; and

i) the apparent right of a conquering nation's intellectuals to both exploit Indigenous Australians and promote their own status and self-esteem by investigative analysis and historical research. ${ }^{28}$

Hart and Whatman conclude that:

Developing research ethics is just one of the strategies that can be employed in reconciling the long history of intrusive study on Indigenous peoples. Looking at more enterprising and collaborative approaches to learning, studying and researching; where a recognition of Indigenous systems of knowledge is given voice and meaning, will mean a rediscovery of this country that has endless potential. The myth of terra nullius implied that this country was uninhabited and terra nullius social policy supported by research enabled for the dispossession of knowledges of Indigenous peoples. It must be remembered that university curriculum, teaching methodologies and research endeavours have a history of development that contributed to this dispossession. Has the time come for change? ${ }^{29}$ 
Re-shaping research within the context of universities inevitably impacts on teaching and learning, and this must be recognised in seeking to enshrine 'Indigenous Education' as a right.

\section{Regional agreements: what are the possibilities?}

The performance of the Australian higher education sector in the four areas of governance, student participation, Indigenous employment and research, points to a need to enshrine the rights articulated in the Coolangatta Statement within enforceable instruments, underpinned by acknowledgement of Aboriginal and Torres Strait Islander sovereignty in the Australian Constitution. Here I offer some suggestions on how the four areas of performance already discussed might relate to Constitutional recognition of Aboriginal and Torres Strait Islander peoples, regional agreements, and other instruments.

\section{University Governance}

As discussed earlier, the governance arrangements for universities are established by state and territory Acts of Parliament. Amending those Acts provides an opportunity to redress the absence of Aboriginal and Torres Strait Islander representation on governing bodies, but how this should occur, what form this representation takes and how such representation relates to Indigenous communities is a matter for serious consideration.

Can Indigenous communities rely on the goodwill of state governments to effect Indigenous representation on university governing bodies, or should there be constitutional recognition by states of Aboriginal and Torres Strait Islander sovereignty to underpin such representation? What mechanisms exist for Indigenous communities to shape how such representation occurs?

The lattermost question above could in part be answered through memoranda of understanding, and two recent examples are relevant.

In Victoria in 2000, the then ATSIC and the Victorian Government signed a communiqué on Indigenous Economic Development, Tourism, Housing, and Cultural Heritage. A priority area which relates to all of these issues is that of education outcomes. Specifically, the Communiqué commits the parties to:

Work to improve education outcomes for Indigenous Victorians, including increased retention of Aboriginal and Torres Strait Islander children in the school system to year 12 and growth in the number of Indigenous students at Victorian universities. ${ }^{30}$

This Communiqué raises the prospect of the Victorian Government fully recognising its responsibilities for restorative justice, and raises the question of Indigenous input to university governance arrangements, a matter discussed earlier in this paper.

A different approach was employed in south-east Queensland (SEQ). The Queensland University of Technology (QUT) and ATSIC were finalising a Memorandum of Understanding (MOU), concerning collaborative activity between the two bodies. The MOU was intended as a pilot for future memoranda, and concentrates on two issues: employment, and capacity building partnerships. 
In employment, the MOU articulates five initiatives:

- Seek to place participants of ATSIC's Graduate Administrative Assistants (GAA) program within suitable areas of QUT, both during the course of their training and after completion.

- QUT will invite trainees in ATSIC's Admin/Clerical Traineeship program (certificate IV) to register their names on QUT's 'expressions of interest' register, for potential employment at QUT.

- Explore the option of using QUT as a work experience area for ATSIC's Admin/Clerical trainees during the course of their traineeship.

- Should QUT develop its own admin/clerical traineeship program, explore areas of collaboration between the two programs such as using ATSIC as a work experience area for QUT trainees, and establishing a trainee network which meets formally and informally.

- Explore partnership possibilities related to growing/developing academic lecturers and researchers from QUT's student body through, for example, post-graduate scholarships; opportunities for employment during their studies ands after graduation; and research/ project opportunities during the course of their study. ${ }^{31}$

The premise of the Capacity Building Partnerships set out in the MOU is that the partners are equal in terms of the expertise they bring to bear, and are committed to build the capacity of each organisation to work together and define common interests. With this in mind, the parties have agreed:

QUT will survey its Faculties and Divisions to map existing partnership activity with Indigenous organisations, and elicit areas of potential interest.

Both organisations will identify and pursue specific opportunities arising from this mapping exercise. ${ }^{32}$

It is foreseeable that in time, both of these documents, in particular the QUT and ATSIC Communiqué, could evolve to address questions of Indigenous Australian involvement in university governance structures. For example, such instruments could provide the opportunity for agreement to be reached between ATSIC and the relevant university (in this case QUT), about how Indigenous representation should be established. This agreement could provide the basis for the parties to approach the State governments seeking amendment of the relevant University Act. Alternatively, the Victorian approach could evolve to a point where such representation is agreed as a matter of principle, (i.e. the Victorian Government will amend University Acts to provide for appropriate Aboriginal representation, and will negotiate with Aboriginal communities to effect such representation) with the details to be determined through negotiation. Additionally, these arrangements could operate in conjunction with, or form a part of, regional agreements within the Native Title Act. ${ }^{33}$

\section{University Indigenous Education Programs}

It should be apparent that the agreements discussed above, i.e. the Memorandum of Understanding and the Communiqué, are in part intended to address Aboriginal and Torres Strait

\footnotetext{
${ }^{31}$ QUT and ATSIC 2002 (verbatim extract). $\quad{ }^{32}$ QUT and ATSIC 2002: $1 . \quad 33$ Native Title Act 1993 (Cth).
} 
Islander participation in university study. Specific programs funded by the Commonwealth such as ABSTUDY have the same objective, but as discussed earlier they are reliant on political goodwill and vulnerable to political bad faith.

Perhaps a constitutional recognition of sovereignty could elaborate other 'Indigenous Rights' such as those set out in the Coolangatta Statement. For example, as the National Aboriginal Conference (NAC) in its interim report on Makarrata proposed 'compulsory teaching of Aboriginal culture in schools, ${ }^{34}$ perhaps there ought to be some recognition of the right of Indigenous people to control Indigenous educational programs. This would be similar to the rights asserted in the Kalkaringi Statement ${ }^{35}$ relating to access to education and control of educational programs, but would extend to the funding schemes which underpin Aboriginal and Torres Strait Islander participation.

\section{University employment of Aboriginal and Torres Strait Islanders}

As the union representing staff in higher education, the NTEU, as a part of its partnership with Indigenous Australians, is committed to the negotiation of legally binding instruments to enshrine the rights asserted by Indigenous peoples. In speaking for this, it has accepted the priority that it needs to start in its own backyard with its own structures and practices.

While the NTEU is not an organisation controlled by Indigenous Australians, its work in pursuing restorative and social justice is informed by respectful dialogue, which seeks to transform the organisation into one which is culturally responsive and responsible. This dialogue has led to a number of changes to the NTEU structure itself, including:

- changes to union rules to provide for Indigenous representation at all levels of the union;

- annual meetings of an Indigenous Members' Forum which determines the directions to be pursued by the union nationally;

- an Indigenous Tertiary Education Policy Committee (ITEPC), which works with union staff to give effect to the objectives stated by Indigenous members; and

- employment of an Indigenous officer, who works in conjunction with the union's policy, industrial and recruitment staff.

A significant initiative identified at the first meeting of the NTEU Indigenous Members' Forum in 1999 was the pursuit of increased levels of employment in universities. This was based on a number of factors, including:

- the Recommendations of the Royal Commission into Aboriginal Deaths in Custody to increase Indigenous employment in the private and public sectors;

- the discontinuation of commonwealth funding for Indigenous employment programs within universities;

- the severe under-representation of Indigenous Australians within the staff profiles of universities, and the implications of this for teaching, research and scholarly activity of relevance to Indigenous Australians;

\footnotetext{
34 See ATSIC 2001. 'Makarrata' is a Yolngu word meaning 'the $\quad{ }^{35}$ Kalkaringi Statement 1998. end of a dispute and the resumption of normal relations'.
} 
- the perception that Indigenous Australian staff were in less secure employment than their non-Indigenous counterparts; ${ }^{36}$

- the need for unions generally to work to redress within the working environment past social injustice, exploitation and Indigenous employment inequality; and

- the need to recognise the diversity that exists within and between Indigenous Australian communities, and in turn the variety of relationships those communities have with universities.

Through the work of the NTEU Indigenous Members' Forum, the ITEPC, and a working party of Indigenous Australian members convened for the purpose, a draft clause was developed for negotiation. The clause sought the agreement of universities to do a number of things, including:

- increase Indigenous Australian employment at all levels of the university;

- commit to the 'Indigenisation' of Indigenous Units/Centres within universities;

- monitor the performance of the university against agreed criteria; and

- ensure that staff selection panels include Indigenous Australian representation;

Importantly, a guiding principle of the enterprise bargaining claim is:

The parties give respect and consideration to the cultural, social and religious systems practiced by Indigenous Australians, recognise Indigenous Australian knowledge as a significant contribution to all other bodies of knowledge, and acknowledge the scholarship that Indigenous Australian employees bring to the University. As far as possible, the parties will actively promote and recognise Indigenous Australian cultural practices and identity. The application of this principle needs to recognise the diversity of Indigenous Australian culture. ${ }^{37}$

It follows therefore, that the implementation of the claim within each university requires appropriate Indigenous Australian oversight. This occurs firstly through the right to direct representation on the negotiation team. The clause itself requires the establishment of a Development and Implementation Committee, with majority Indigenous Australian representation drawn from university staff and within the community. In this respect, the bargaining clause can be articulated to other legally binding instruments, such as those described above.

\section{University Research}

Clearly, all three of the mechanisms discussed above have some capacity to affect the way in which research is conducted on matters of importance to Indigenous Australians. A step toward shaping such research so that it more closely reflects Indigenous Australian community priorities might include the notion of co-supervision of postgraduate research, which has been advocated by the NTEU in its submission to the recent Senate Inquiry into Higher Education. ${ }^{38}$

\footnotetext{
${ }^{36}$ This perception was borne out by the results $\quad 37$ NTEU 1999a: para 1. of the NTEU research discussed above. $\quad 38$ NTEU 2001.
} 
Co-supervision would involve appropriately informed and recognised (from Indigenous community perspectives) Aboriginal and Torres Strait Islander people to work in conjunction with the designated supervisor, usually although not always, a non-Indigenous academic.

How such supervision could be arranged can be informed by dialogue occurring in the administration of agreements such as those addressed above. It may be necessary to include the matter of postgraduate supervision within instruments like the Communiqué (Victoria) or the Memorandum of Understanding (Queensland).

\section{Conclusion}

Agreements such as those discussed here represent a step forward in transforming educational institutions so that they are more culturally responsive and responsible to the rights of Indigenous Australians in higher education. Such agreements can refer to more formal regional agreements, such as those contemplated by the Native Title Act, and provide a degree of flexibility that allows adaptation to local circumstances. How these agreements can relate to a formal constitutional recognition of Aboriginal and Torres Strait Islander sovereignty must be discussed within the broader conversation about a treaty.

The process of making Indigenous Education an enshrined right, rather than a matter of administrative or political goodwill, must continue so that the benefits of the education system are available to all Aboriginal and Torres Strait Islander peoples. It must also continue in order to transform teaching and learning for all Australians so that it truly depicts Indigenous Australian reality: not only at university, but also in turn through the school system.

\section{Acknowledgments}

This paper has been informed by many discussions, observations and experiences. I would firstly like to thank the many Aboriginal and Torres Strait Islander people who have had the time and patience to impart their understanding during my work with them. I also thank the members of the National Tertiary Education Union Indigenous Members' Forum, who have contributed their wisdom and commitment to the important work of redressing Indigenous educational disadvantage. Of these members, I would particularly like to thank Dr Bob Morgan, Associate Professor Tracey Bunda, and Victor Hart, for their ongoing contributions to this area. My sincere thanks also go to my djaambi Joel Wright, NTEU Indigenous Officer. 


\section{References}

\section{Books, articles and reports}

AIATSIS 1999, Research of Interest to Aboriginal and Torres Strait Islander peoples, National Board of Employment, Education and Training, Australian Research Council, Canberra.

ATSIC and the Victorian Government 2000, Communiqué, 22 June, $2 \mathrm{pp}$.

ATSIC 2001, 'Treaty Now', Treaty Secretariat, National Policy Office, ATSIC, Woden, ACT.

Brah, A 1992, 'Difference, Diversity and Differentiation' in J McDonald, J Rattansi and A Rattansi (eds) Race, culture and difference, Open University Press, Milton Keynes: 126-45.

Bunda, T and G McConville 2002, 'Indigenous higher education, myths, cuts and obvious decline', Campus Review, 29 May-2 June: 3-18.

Coolangatta Statement on Indigenous peoples' Rights in Education 1999, World Indigenous Peoples' Conference on Education, Hilo, Hawaii.

Cordell, J 1995, Indigenous management of land and sea and traditional activities in Cape York Peninsula, Cape York Peninsula Land Use Strategy, Brisbane.

Council of Australian Postgraduate Associations (CAPA) 1997, Barriers facing Indigenous postgraduate students, CAPA, Melbourne.

Deakin University 1999, Analysis of the Proposed Changes to ABSTUDY on Indigenous Students, Final Report, May, Deakin University, Melbourne.

DEET 1993, National Aboriginal and Torres Strait Islander Education Policy - Second Triennium 1993-1995, AGPS, Canberra.

DEST 2002, Higher Education Report for the 2002 to 2004 Triennium, AGPS, Canberra.

DETYA 1999a, Staff 1999, Selected Higher Education Statistics, DETYA, Canberra.

— 1999b, Students 1999, Selected Higher Education Statistics, DETYA, Canberra.

— 2000a, Higher Education Staff Statistics, AGPS, Canberra.

- 200ob, Indigenous Participation in Higher education, Higher Education Division Occasional Papers, DETYA, Canberra.
— 2000c, Staff 2000, Selected Higher Education Statistics, DETYA, Canberra.

— 2000d, Students 2000, Selected Higher Education Statistics, DETYA, Canberra.

Donovan, RJ and R Spark 1997, ‘Towards guidelines for survey research in remote Aboriginal communities', Australian and New Zealand Journal of Public Health 21 (1): 89-95.

Durnan, D and J Boughton 1999, Succeeding against the odds: The outcomes attained by Indigenous students in Aboriginal community-controlled adult education colleges, NCVER (National Centre for Vocational Education Research), Kensington Park, SA.

Eisenhart, MA and KR Howe 1992, 'Validity in Educational Research' in MP Le Compte, WL Millroy and J Geissle (eds) The Handbook of Qualitative Research in Education, Academic Press, London: 643-80.

Fannon, F 1967, The wretched of the earth, Penguin, Harmondsworth.

Flick, B 1995, 'Spiritual Healing, Land and Health', Aboriginal and Islander Health Worker Journal 19(1): 3-5.

Fredericks, B 1996, 'CAPA Indigenous Postgraduate Project - Progress Report', seminar paper presented at the 1996 QUT Oodgeroo Unit Indigenous Postgraduate Forum, 31 October, Queensland University of Technology, Brisbane.

Harri, A 1994, A good idea waiting to happen: regional agreements in Australia, Proceedings from the Cairns workshop, Cape York Land Council, Cairns, Nth Qld, July.

Hart, V and S Whatman 1998, 'Decolonising the concept of knowledge', paper presented at HERDSA98 Conference in Auckland, Queensland University of Technology, Brisbane, available at http://www.qut.edu.au/chan/oodgeroo/hart.htm

James Cook University 1995, Indigenous Research Ethics, Proceedings of the 1995 Indigenous Research Ethics Conference, James Cook University, Townsville.

Jull, P 1994, Australian nationhood and outback Indigenous peoples, North Australia Research Unit, Australian National University, Casuarina. 
Kalkaringi Statement 1998, Constitutional Convention of the Combined Nations of Central Australia, Kalkaringi, August 17-20.

Kari Oca Statement 1993, Indigenous Peoples' Earth Charter, Brazil.

Keilor Historical Society 1992, Newsletter, September/ October 1992.

Lincoln, Y and E Guba 1985, Naturalistic Inquiry, Sage, Beverley Hills, CA.

Lui Jnr, G 1994, 'Torres Strait: Towards 2000’, Race and Class 35(4): 11-20.

Manne, R 2001, 'In Denial: The Stolen Generations and The Right', The Australian Quarterly Essay, 1/2001, Schwartz, Melbourne.

Middleton, S 1996, 'Doing Qualitative Research in the Mid-1990s: Issues, Contexts and Practicalities', Waikato Journal of Education 2: 3-23.

Miles, M and A Huberman1994, Qualitative Data Analysis : An Expanded Sourcebook, Sage, Thousand Oaks, California.

Nakata, M 1995, 'Cutting a Better Deal for Torres Strait Islanders', The Aboriginal Child at School 23(3): 20-7.

— 1997, 'Who’s reading “Misplaced Hopes”?', Qualitative Studies in Education 10(4): 425-31.

NTEU 1999 (unpublished), Indigenous Employment Strategy Clause.

2000 (unpublished), Survey of Indigenous Centres in Universities.

— 2001, NTEU Indigenous Tertiary Education Policy Committee Submission to the Senate Employment, Workplace Relations, Small Business and Education References Committee Inquiry into the capacity of public universities to meet Australia's higher education needs, May.

Queensland University of Technology (QUT) and Aboriginal \& Torres Strait Islander Commission (ATSIC) 2002, Draft Memorandum of Understanding, ATSIC, Canberra.

Royal Commission into Aboriginal Deaths In Custody 1991, National Report Overview and Recommendations (by Commissioner Elliott Johnson), AGPS, Canberra.

Runciman, C 1994, Elevating Choice : A study of Aboriginal women's labour market participation in South East Queensland, AGPS, Canberra.
Scheurich, J 1997, 'From the Editors: Postcolonialism, feminism, critiques, history, caring and fidelity, and telephone talks with mom - we've got it all', Qualitative Studies in Education 10(4): 403-6.

Stake, R 1994, 'Case Studies' in NK Denzin and YS Lincoln (eds) Handbook of Qualitative Research, Sage, Thousand Oaks: 236-47.

Stanley, $O$ and G Hansen 1998, ABSTUDY: An investment for tomorrow's employment. A review of ABSTUDY for the Aboriginal and Torres Strait Islander Commission, Commonwealth of Australia, Canberra.

Taylor, J 1991, Spatial mobility of working age Aborigines in settled and remote Australia: a preliminary analysis, Centre for Aboriginal Economic Policy \& Research, Australian National University, Canberra.

Taylor, J and B Hunter 1998, The job still ahead: Economic costs of continuing Indigenous employment disparity, ATSIC, Canberra.

University of Tasmania 1997, Ethical guidelines for research projects and teaching exercises using human subjects, University of Tasmania, Hobart.

\section{Legislation}

Batchelor Institute of Indigenous Tertiary Education Act 1999 (Northern Territory).

Charles Sturt University Act 1989 (New South Wales). Native Title Act 1993 (Cth).

\section{Case Law}

Mabo v Queensland (No 2) 175 CLR 1. 